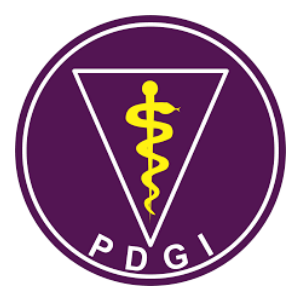

\title{
The Comparison of Metronidazole, Clindamycin, and Amoxicillin Againts Streptococcus sanguinis
}

\author{
Kevin Lim ${ }^{1}$, Armelia Sari Widyarman ${ }^{2 \S}$ \\ ${ }^{1}$ Undergraduate student, Faculty of Dentistry, Trisakti University, Indonesia \\ 2 Department of Microbiology, Faculty of Dentistry, Trisakti University, Indonesia
}

Received date: August 15, 2018. Accepted date: September 27, 2018. Published date: October 19, 2018

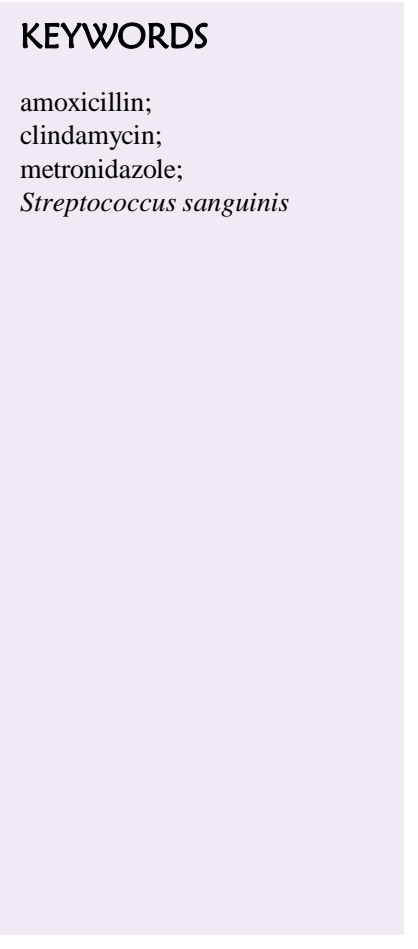

\begin{abstract}
Introduction: Viridans streptococci group such as Streptococcus sanguinis (S. sanguinis), an anaerobic Gram-positive bacteria is a well-known for its involvement in dry socket (alveolar osteitis)-associated infection. Systemic amoxicillin, clindamycin and metronidazole have all been shown to be effective to inhibit this bacterium. However, there has been a lack of studies identifying which are the most effective amongst these antibiotics toward Streptococcus sanguinis. Objectives: The purpose of this study is to evaluate the effectiveness of metronidazole, clindamycin, and amoxicillin in inhibiting the growth of Streptococcus sanguinis in vitro. Methods: This effectiveness was done by using agar well diffusion methods. S. sanguinis ATCC 10556 were cultured in Brain Heart Infusion (BHI) broth at $37^{\circ} \mathrm{C}$ under anaerobic condition. After $48 \mathrm{~h}$, bacterial cells were harvested and counted using microplate reader $(490 \mathrm{~nm})$ to achieve optical density of $0.25-0.30\left(10^{7} \mathrm{CFU} / \mathrm{mL}\right)$. Subsequently, $100 \mu \mathrm{L}$ of bacterial suspension was cultured on BHI agar and each antibiotic suspension was added into each agar well, incubated for $72 \mathrm{~h}$ at $37^{\circ} \mathrm{C}$. The inhibition zone diameters were measured with electronic caliper. All experiments were done in triplicate, and repeated two times in separated occasions. The obtained data were statistically analyzed using one-way ANOVA test. A p $<0.05$ was considered as significance. Result: The results showed that there was a significant difference in the effectiveness, clindamycin and amoxicillin in inhibiting the growth of Streptococcus sanguinis $(\mathrm{p}<0.05$ ), compared to metronidazole. The inhibition zone diameter with mean \pm SD $(\mathrm{mm})$ are $13.50 \pm 2.0,34.67 \pm 2.3$ and $32.67 \pm 1.7$ for metronidazole, clindamycin and amoxicillin, respectively. Conclusion: Clindamycin and amoxicillin are more effective in inhibiting the growth of Streptococcus sanguinis compared to metronidazole in this study. However, future studies are needed to confirm this result in vivo.
\end{abstract}




\section{INTRODUCTION}

The most common bacteria associated with dry socket-related infection, one of common complications of post extraction case are the viridans group of streptococci such as Streptococcus viridans (S. viridans). $S$. viridans can be found in the oral cavity, oropharynx, gastrointestinal tract, and genitourinary. ${ }^{1,2}$ Study has reported that the most common organism isolated from a root canal is Streptococcus $\alpha$-haemolyticus, a group that includes $S$. viridans. ${ }^{3}$ In dentistry, S. viridans has been known as the cause of odontogenic infection. ${ }^{4} S$. sanguinis is part of the $S$. viridans group, a facultative anaerobic Gram-positive bacteria, which is a normal member of the microflora in the human oral cavity. ${ }^{5}$ Topical and systemic antibiotics can decrease the dry socket incidence rate by preventing the related bacterium growth. The use of antibiotics such as clindamycin and amoxicillin are effective to treat the dry socket-associated infection. ${ }^{6}$

Metronidazole is used to treat many broad-spectrum infections by stopping bacterial or parasitic growth. ${ }^{7}$ Metronidazole is highly effective against anaerobic Gram-positive and Gram-negative bacteria. Oral administration of this antibiotic will be well absorbed, spread systemically, and can reach up to $4-6 \mu \mathrm{g} / \mathrm{mL}$ of serum levels if $250 \mathrm{mg}$ of metronidazole was taken. ${ }^{8}$ Metronidazole is metabolized in the liver through oxidation, hydroxylation, and conjugation process. In particular, this antibiotic is known for its effectiveness against anaerobic Gram-positive Streptococcus viridans, including S. sanguinis. ${ }^{9}$

Clindamycin (a derivative form of lincomycin) is another effective antibiotic against Gram-positive and Gram-negative bacteria. ${ }^{10}$ Compared to lincomycin, clindamycin has been prescribed more frequently because it has better absorption through the gastrointestinal lining, leads to a higher concentration of the medicine in the serum. Although lincomycin has the same spectrum and mechanism as clindamycin, lincomycin has less effectiveness both in vitro and in vivo as compared to clindamycin. ${ }^{11}$

Amoxicillin is a broad-spectrum penicillin group, and is highly effective against Gram-positive bacteria that do not produce $\beta$-lactamase. ${ }^{12}$ If taken orally, amoxicillin is more stable in acidic conditions without being affected by foods, has lower incidence of diarrhea, and can be absorbed better than ampicillin in the gastrointestinal tract. Orally administered amoxicillin is effective against facultative Streptococcus bacteria. ${ }^{13}$

Systemic metronidazole, clindamycin and amoxicillin are all effective against oral pathogen. However, there is a lack of studies identifying which of these antibiotics is the most effective toward dry socket infection. The objective of this study is to evaluate the effectiveness of metronidazole, clindamycin, and amoxicillin in inhibiting the growth of $S$. sanguinis in vitro.

\section{MATERIALS AND METHODS}

\section{Preparation of the Metronidazole, Clindamycin and Amoxicillin Solutions}

A tablet containing $500 \mathrm{mg}$ of metronidazole and a tablet containing $500 \mathrm{mg}$ of amoxicillin were crushed separately into powder and diluted in $2 \mathrm{~mL}$ of aquadest. A capsule containing $300 \mathrm{mg}$ of clindamycin was diluted in $1.2 \mathrm{~mL}$ of aquadest. The concentration of each solution was set to be $25 \%$ in a $1.5 \mathrm{~mL}$ microcentrifuge tube.

\section{Streptococcus sanguinis Culture}

S. sanguinis ATCC 10556 was obtained from MiCORE Laboratory, Faculty of Dentistry, at Trisakti University. The bacterium was cultured in brain heart infusion (BHI) medium broth (Thermo Fisher Scientific, USA) and incubated at $37^{\circ} \mathrm{C}$ for $48 \mathrm{~h}$ under anaerobic conditions using gaspack jar system. ${ }^{14,15}$

\section{Minimum Inhibititory Concentration (MIC) Test}

The metronidazole, clindamycin, and amoxicillin inhibition zone tests were performed using the agar well diffusion method. Each plate containing the agar medium was punctured using a perforator to create a well with a 5 $\mathrm{mm}$ diameter and was labelled with the name of each antibiotic. The wells were filled with $50 \mu$ of the metronidazole, clindamycin and amoxicillin solutions, respectively. A plate of 3 wells containing aquadest was used as a negative control. All petri dishes were incubated for $24 \mathrm{~h}$ at $37^{\circ} \mathrm{C}$ in anaerobic atmosphere as mentioned above. The resulted inhibition zone diameters were measured with an electronic caliper. All treatments were done in triplicate, and repeated two times.

\section{RESULT}

The results showed that there was a significant difference in the effectiveness of clindamycin and amoxicillin in inhibiting the growth of Streptococcus sanguinis $(\mathrm{p}<0.05)$. The result of the MIC test showed that inhibition zones were formed after $24 \mathrm{~h}$ of incubation. The test found that metronidazole had a mean value of $13.50 \pm 2.0 \mathrm{~mm}$ for its inhibition zone against $S$. sanguinis, clindamycin measured $34.67 \pm 2.3 \mathrm{~mm}$, and amoxicillin $32.67 \pm 1.7 \mathrm{~mm}$ (Fig.1 \& Fig.2). The normality test showed the data to be normally distributed with a value 
of $p>0.05$. The one-way ANOVA test showed that there was a significant difference between metronidazole, clindamycin, and amoxicillin in inhibiting the growth of S. sanguinis bacteria $(\mathrm{p}=0.000)$.

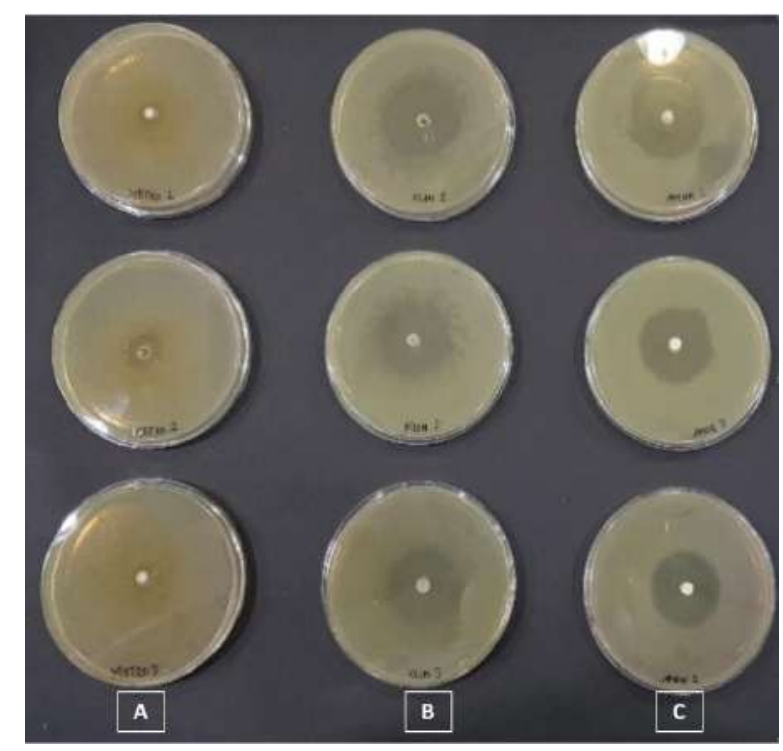

Figure 1. Inhibition zones of metronidazole (A), clindamycin (B), and amoxicillin (C) against Streptococcus sanguinis tests were performed using the agar well diffusion method. All treatments were done in triplicate.

\section{MEAN VALUE OF ANTIBIOTIC INHIBITION RATE AGAINST $S$. sanguinis BACTERIA}

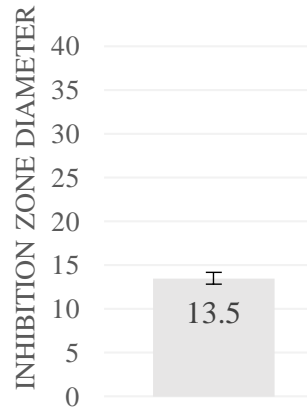

METRONIDAZOLE

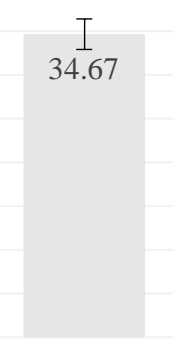

CLINDAMYCIN ANTIBIOTICS

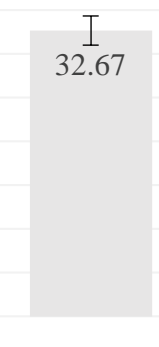

AMOXICILLIN
Figure 2. The graphic above shows the mean value of the inhibition zones against Streptococcus sanguinis after addition of metronidazole, clindamycin, and amoxicillin solutions in their respective wells. The metronidazole solution demonstrated the lowest inhibition zone $(13.5 \mathrm{~mm})$, while clindamycin had the highest inhibition zone with a mean of $34.67 \mathrm{~mm}$. The amoxicillin solution's inhibition zone was $32.67 \mathrm{~mm}$.

\section{DISCUSSION}

The results of this study demonstrated that there was a significant difference in the inhibitory activity of clindamycin and amoxicillin against $S$. sanguinis, compared to the control. In this study, metronidazole that used as a control, showed the lowest $(\mathrm{p}<0.05)$ inhibitory activity compared to the other tested antibiotics (clindamycin and amoxicillin).On the other hand, there was no significant difference between clindamycin and amoxicillin inhibition activity against the bacterium tested.

Metronidazole is an antibiotic that belongs to nitroimidazole group. ${ }^{7}$ After being diffused into the intracellular protein transport of an organism, metronidazole interacts with its DNA by damaging the DNA helix structure. This will lead to DNA breakage and the inhibition of protein synthesis, causing the death of this organism. ${ }^{16}$ This antibiotic has complete success in inhibiting anaerobic bacteria such as Bacteriodes sp. (including Bacteroides fragilis), Fusobacterium and Clostridium sp. (including Clostridium difficile). ${ }^{17}$

The antimicrobial activity of clindamycin includes aerobic Gram-positive bacteria, anaerobic Gram-positive and Gram-negative bacteria, and certain species of protozoa. Clindamycin can be considered bacteriostatic or bactericidal, depending on the bacterial species. It has a high activity against Gram-positive cocci, including $S$. pneumoniae, $S$. viridans, $S$. pyogenes, and $S$. aureus. ${ }^{11}$ Lincosamide antibiotics bind to the 23S rRNA of the 50S ribosomal subunit, thus interfering and inhibiting protein synthesis and leading to subsequent cell death. ${ }^{18}$ Clindamycin generates a higher serum level, thus it is considered a more potent drug than lincomycin. ${ }^{19}$

Amoxicillin is a semi synthetic antibiotic that belongs to the $\beta$-lactam penicillin group. As the most common antibiotic prescribed by dentists, it treats broadspectrum antimicrobial infections with a bacteriolytic mechanism. ${ }^{20}$ It is effective against Gram-positive and Gram-negative bacteria. Generally, this antibiotic is effective against bacteria such as Streptococcus, Bacillus subtilis, Enterococcus, Haemophilus, Helicobacter, and Moraxella. This antibiotic is highly effective against $\beta$ lactamase non-producing Gram-positive bacteria and can be easily diffused into the Gram-negative bacterial cell wall compared to benzilpenicillin. ${ }^{21}$ The mechanism of amoxicillin is to inhibit the synthesis of the wall cell of the bacteria by binding one-to-another along penicillinprotein bonds (PBPs-Protein Binding Penicillin). These bonds inhibit the ending of trans-peptidase peptidoglycan synthesis in a bacterial cell, preventing biosynthesis and rupturing the cell. ${ }^{22}$

Both Gram-positive and Gram-negative bacterial cell walls are susceptible to the mechanism of this antibiotic. Gram-negative bacteria are more prone to develop resistance against this antibiotic because they contain thinner layer of cell wall compared to Gram-positive bacteria, ${ }^{23}$ but Gram-positive bacteria (including viridans 
group streptococci) can also develop such a defense mechanism toward penicillin antibiotics. ${ }^{24}$

This study shows that the metronidazole solution has the smallest inhibition zone compared to clindamycin and amoxicillin. A clinical study of metronidazole as a preand post-operational treatment, which reported that there was insignificant decrease in the incidence of dry socket. ${ }^{25}$ These results are in agreement with Mombelli et al. (2015) which states that the Streptococcus viridans group showed less susceptibility to metronidazole, as the viridans group of streptococci were more prone to develop resistance genes to antibiotics. Therefore, the synergistic effects of metronidazole and other antibiotic combinations, such as amoxicillin, have been highly suggested. ${ }^{26}$

The results of this study also showed that the clindamycin solution has the largest inhibition zone, which had a mean value $34.67 \mathrm{~mm}$. The clindamycin solution therefore has strongest inhibition effect against Streptococcus sanguinis. A comparative study between clindamycin and ampicillin (belonging to the penicillin group) was conducted to treat odontogenic infections. ${ }^{27}$ According to the results of this study, clindamycin was considered to be more effective than ampicillin in eradicating odontogenic bacteria. ${ }^{28}$ No resistance against this antibiotic was observed in any of the isolates, whereas the prevalence of ampicillin resistance among those isolates was quite high ${ }^{27,28}$ conducted another study to look at the susceptibility of the viridans group of streptococci in blood samples to eight different antibiotics (including amoxicillin and clindamycin).

It has been reported that clindamycin was more effective and efficient against $S$. sanguinis in vitro, because clindamycin had relatively lower MIC values than amoxicillin. The $\mathrm{MIC}_{50}$ value of clindamycin was $0.047 \mathrm{mg} / \mathrm{L}$, while the $\mathrm{MIC}_{50}$ value for amoxicillin was $0.094 \mathrm{mg} / \mathrm{L}$. Clindamycin has a $\mathrm{MIC}_{90}$ value of 0.19 $\mathrm{mg} / \mathrm{L}$, while amoxicillin has a $\mathrm{MIC}_{90}$ value of $4.0 \mathrm{mg} / \mathrm{L}$ due to the resistance of the viridans group of streptococci. This result was compatible with Triegel and Schlagel's statement, that the etiology of dry socket is related to anaerobic bacterial infection and clindamycin is effective in preventing dry socket. ${ }^{29}$

\section{CONCLUSION}

Based on this research, it can be concluded that there was a difference in the inhibition effect among metronidazole, clindamycin, and amoxicillin. Clindamycin and amoxicillin are more effective in inhibiting the growth of Streptococcus sanguinis compared to metronidazole since Streptococcus sanguinis is a bacterium most commonly reported for its involvement in dry socket's case. However, future studies are needed to confirm this result in vivo.

\section{CONFLICT OF INTEREST}

The authors declare that there are no conflict of interest.

\section{REFERENCES}

1. Mamoun J. Dry socket etiology, diagnosis, and clinical treatment techniques. J Korean Assoc Oral Maxillofac Surg. 2018;44(2):52-8.

2. Alexander RE. Dental extraction wound management: a case against medicating postextraction sockets. J Oral Maxillofac Surg Off J Am Assoc Oral Maxillofac Surg. 2000;58(5):53851.

3. Narayanan LL, Vaishnavi C. Endodontic microbiology. J Conserv Dent JCD. 2010;13(4):2339.

4. Chunduri NS, Madasu K, Goteki VR, Karpe T, Reddy H. Evaluation of bacterial spectrum of orofacial infections and their antibiotic susceptibility. Ann Maxillofac Surg. 2012;2(1):46-50.

5. Patterson MJ. Streptococcus. In: Baron S (ed). Medical Microbiology. University of Texas Medical Branch at Galveston: Galveston (TX); 1996 http://www.ncbi.nlm.nih.gov/books/NBK7611/

6. Akinbami BO, Godspower T. Dry Socket: Incidence, Clinical Features, and Predisposing Factors. Int J Dent. 2014;2014. doi:10.1155/2014/796102.

7. Samuelson J. Why metronidazole is active against both bacteria and parasites. Antimicrob Agents Chemother . 1999;43(7):1533-41.

8. Heta S, Robo I. The side effects of the most commonly used group of antibiotics in periodontal treatments. Med $\quad$ Sci. doi:10.3390/medsci6010006.

9. Tuohy M, Washington JA. Antimicrobial susceptibility of viridans group streptococci. Diagn Microbiol Infect Dis. 1997;29(4):277-80.

10. Smieja M. Current indications for the use of clindamycin: A critical review. Can J Infect Dis. 1998; 9(1):22-8.

11. Lippincott's guide to infectious diseases. 3rd edition. Philadelphia: LWW; 2003.

12. Langdon A, Crook N, Dantas G. The effects of antibiotics on the microbiome throughout development and alternative approaches for therapeutic modulation. Genome Med. 2016;8:39. doi:10.1186/s13073-016-0294-z.

13. Kuehn J, Ismael Z, Long PF, Barker CIS, Sharland M. Reported rates of diarrhea following oral penicillin therapy in pediatric clinical trials. J Pediatr Pharmacol Ther . 2015;20(2):90-104.

14. Widyarman AS, Yunita ST, Prasetyadi T. Consumption of yogurt containing probiotic 
Bifidobacterium lactis reduces Streptococcus mutans in orthodontic patients. Sci Dent J. 2018;2(1):19-25.

15. Widyarman AS, Hartono V, Marjani L, Irawan D, Luthfi L, Bachtiar BM. Lactobacillus reuteri containing probiotic lozenges consumption reduces Streptococcus mutans, Streptococcus sobrinus, Porphyromonas gingivalis, and Aggregatibacter actinomycetemcomitans in orthodontic patients. J Int Dent Med Res. 2018;11(2):628-33.

16. Uzlikova M, Nohynkova E. The effect of metronidazole on the cell cycle and DNA in metronidazole-susceptible and -resistant Giardia cell lines. Mol Biochem Parasitol. 2014;198:75-81.

17. Leitsch D. A review on metronidazole: an old warhorse in antimicrobial chemotherapy. Parasitology. 2017;23:1-12.

18. Morar M, Bhullar K, Hughes DW, Junop M, Wright GD. Structure and mechanism of the lincosamide antibiotic adenylyltransferase LinB. Struct Lond Engl. 2009;17(12):1649-59.

19. Scholar EM, Pratt WB (eds.). The antimicrobial drugs. 2nd Edition. New York: Oxford University Press; 2000.

20. Peedikayil FC. Antibiotics in odontogenic infections - an update. J Antimicrob Agents. 2016;2(2):1-3.

21. Credito KL, Lin G, Pankuch GA, Bajaksouzian S, Jacobs MR, Appelbaum PC. Susceptibilities of Haemophilus influenzae and Moraxella catarrhalis to ABT-773 compared to their susceptibilities to 11 other agents. Antimicrob Agents Chemother. 2001; 45(1):67-72.

22. Kohanski MA, Dwyer DJ, Collins JJ. How antibiotics kill bacteria: from targets to networks. Nat Rev Microbiol. 2010;8(6):423-35.

23. Zeng $X$, Lin J. Beta-lactamase induction and cell wall metabolism in Gram-negative bacteria. Front Microbiol. 2013;4:128.

24. Alcaide F, Liñares J, Pallares R, J carratala, MA Benitez, F Gudiol, et al. In vitro activities of 22 betalactam antibiotics against penicillin-resistant and penicillin-susceptible viridans group streptococci isolated from blood. Antimicrob Agents Chemother. 1995;39(10):2243-7.

25. Blum IR. Contemporary views on dry socket (alveolar osteitis): a clinical appraisal of standardization, aetiopathogenesis and management: a critical review. Int J Oral Maxillofac Surg. 2002; 31(3):309-17.

26. Mombelli A, Cionca N, Almaghlouth A, Cherkaoui A, Schrenzel J, Giannopoulou C. Effect of periodontal therapy with amoxicillin-metronidazole on pharyngeal carriage of penicillin- and erythromycin-resistant viridans streptococci. J Periodontol. 2016;87(5):539-47.

27. Mangundjaja S, Hardjawinata K. Clindamycin versus ampicillin in the treatment of odontogenic infections. Clin Ther. 1990;12(3):242-9.

28. Smith A, Jackson MS, Kennedy H. Antimicrobial susceptibility of viridans group streptococcal blood isolates to eight antimicrobial agents. Scand J Infect Dis. 2004;36(4):259-63.

29. Kupfer SR. Prevention of dry socket with clindamycin. A retrospective study. N Y State Dent J. 1995; 61(6):30-3. 